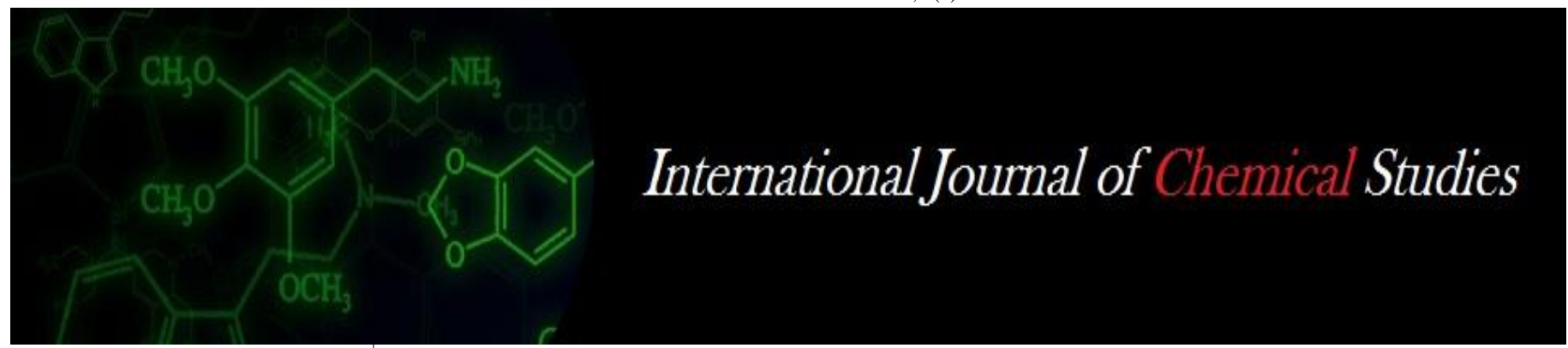

P-ISSN: 2349-8528

E-ISSN: 2321-4902

www.chemijournal.com

IJCS 2020; 8(2): 2633-2638

(C) 2020 IJCS

Received: 15-01-2020

Accepted: 21-02-2020

\section{Abhinandita Sahoo}

Department of Plant Pathology,

M. S. Swaminathan School of

Agriculture, Centurion

University of Technology and

Management, Paralakhemundi,

Odisha, India

Amitava Basu

Department of Plant Pathology,

BCKV, West Bengal, India

\section{Evaluation of antimicrobial property of nano- formulation and inducer chemical against Colletotrichum capsici on chilli}

\author{
Abhinandita Sahoo and Amitava Basu
}

DOI: https://doi.org/10.22271/chemi.2020.v8.i2an.9148

\begin{abstract}
Chilli (Capsicum annuum) is one of the most important solanaceaus crop in India. Chilli crop affected by a large no of foliar disease. Among them, chilli anthracnose caused leaf blight and fruit rot is one of the most important diseases causing heavy yield loss. Hence, an efficient research studies carried out related to management of agricultural important pathogen of chilli crop. Under in-vitro study seven chemical namely silver Nanoparticle (AgNPs), $\mathrm{AgNO}_{3}$, Silvox $\left(\mathrm{H}_{2} \mathrm{O}_{2}+\mathrm{AgNO}_{3}\right)$, Chitosan, Salicylic acid, $\mathrm{H}_{2} \mathrm{O}_{2}$, Isoprotiolane (check chemical) were evaluated in different concentration against fungal pathogen Colletotrichum capsici, under in-vitro and in-vivo condition. In in-vitro condition out of seven chemical $\mathrm{H}_{2} \mathrm{O}_{2} @ 9.66$ ppm appeared to be most effective which was followed by Silvox (12.07 ppm) in respect of mycellial growth inhibition against Colletotrichum capsici as compared to check chemical Isoprothiolane. In-vivo condition it recorded that curative application of nano-formulation resulted significant disease suppression at 50ppm (Silver Nanoparticle-(AgNPs)-80.96\%, $\mathrm{AgNO}_{3}-60.0 \%$, Silvox$84.01 \%$ and Chitosan-61.93\%) as compared to check chemical Isoprothiolane (57.93\%)at 50ppm.
\end{abstract}

Keywords: Chilli, Colletotrichum capsici, In-vitro and In-vivo

\section{Introduction}

The Solanaceae (nightshades) is one of the most important plant families and has extensive economic importance (Hawkes 1999) ${ }^{[5]}$. Among the Solanaceous crop chilli (Capsicum annuum) is one of important crop grown in India. It affected by a large number of fungal disease among them anthracnose caused by Colletotrichum capsici is of major concern in chilli producing areas of India as it reduces yield and marketable value of the crop by 10-80\% (Poonpolgul and Kumphai, 2007) ${ }^{[13]}$. Typical anthracnose symptoms on chilli fruit include sunken necrotic tissues, with concentric rings of acervuli. Fruits showing blemishes have reduced marketability (Manandhar et al., 1995) ${ }^{[8]}$. So it should be necessary to attain effective diseases control against such pathogenic fungi. For the control of this disease, agrochemicals have been used for a long time. But wide spread use of agrochemicals has certainly decreased the outbreak of fungal diseases but at the same time has contributed to the development of resistant pathogens (Lamsal et al., 2011) ${ }^{[6]}$ along with it can be lethal to beneficial microorganisms in the rhizosphere and useful soil insects and they may also enter the food chain and cause biomagnifications. Therefore the potential applications of nonmaterial, inducer chemicals and new systemic fungicides in crop protection helps in the development of efficient strategies for the eco-friendly management of plant pathogens under sustainable agriculture. In recent years, nanotechnology has been increasingly applied to the development of novel antimicrobials for the management of pathogen affecting agricultural crops, humans and animals. A number of patents and products integrating nanomaterials into agricultural practices (e.g., nano pesticides, nano fertilizers, and nano sensors) have been developed. A number of different types of induced resistance have been defined based on differences in signalling pathways and spectra of effectiveness, including systemic resistance and induced systemic resistance. Such resistance can be induced in plants by application of a variety of biotic and abiotic agents. The resulting resistance tends to be broad-spectrum having long lasting, effect for disease by between 20 and $85 \%$. Although research in this area has been increased over last few years. There have also been a number of studies required for understanding of how best to use induced resistance along with nano-formulations in practical crop protection.
Corresponding Author:

Department of Plant Pathology, BCKV, West Bengal, India 


\section{Materials and Methods}

The present research was conducted in Bidhan Chandra Krishi Viswavidyalaya (Department of Plant Pathology). Potatodextrose-agar (PDA) medium was used for isolation of fungus Colletotrichum capsici.

\section{Identification of the Fungal Culture}

Morphological and cultural characters of isolated fungi was recorded and compared with standard text for establishing their identity (Booth and Sutton, 1984; Chowdhry, et al., 2000) $[2,3]$

\section{In-vitro evaluation of Chemicals Using Poisoned Food Technique}

Potato dextrose agar amended with different nano formulation, plant inducer, ROS molecule and the final concentration of different nano formulations, ROS molecules and plant inducer are $1 \mathrm{ppm}, 5 \mathrm{ppm}, 10 \mathrm{ppm}, 15 \mathrm{ppm}, 20 \mathrm{ppm}$ and control. The control is amended with sterile distilled water without any formulation with three replication of each treatment. Observation on radial growth were measured in both nano-formulation and different plant inducer chemicals amended media and untreated control and extended of incubation of mycelia growth by each formulation was calculated by estimating the percent reduction in mean mycelia radial growth over that control (Vincent, 1947) ${ }^{[14]}$.

Inhibition $\%=\frac{\mathrm{C}-\mathrm{T}}{\mathrm{C}} \times 100$

The poisoned food technique (Falck, 1907) was followed to evaluate the efficacy of chemicals, in this technique different concentrations of the test chemicals are mixed with the nutrient medium (PDA) and then test organism is allowed to grow in such medium.
Effect of Chemicals against Different Foliar Diseases on Chilli Crops under Net House Condition

Under net house condition, different chemicals were applied 1 day before spore inoculation and 1 day post inoculation on chilli crop. Forty five days old plant of chilli, with different nano formulations and plant inducer chemicals molecule with different concentrations i.e., $25 \mathrm{ppm}$ and $50 \mathrm{ppm}$. The control is modifying with sterile distilled water without any formulation with three replication of each treatment. Spore obtained from the actively growth expanding of 7-9 days old colony of each isolated pathogens and inoculated to plants. Observations were taken after 10 days. Disease severity calculated by scoring the diseases following 0-9 scale of Mayee and Datar (1986) ${ }^{[9]}$.

$$
\text { Disease Severity }(\%)=\frac{\text { sum of all numerical rating }}{\text { No.of leaves examined } \times \text { Maximum disease rating }} \times 100
$$

The disease severity was recorded at $7,14,21$ days and 28 days after onset of disease in all tested crops

\section{Result and discussion}

In-vitro evaluation of chemicals against isolated foliar fungal pathogens Colletotrichum capsici on Chilli

From the Table (1) and Plate(1) reveals that out of seven chemicals considered for the in-vitro study. $\mathrm{H}_{2} \mathrm{O}_{2} @ 9.66 \mathrm{ppm}$ appeared to be most effective in respect of mycellial growth inhibition against the pathogen Colletotrichum capcisi followed by Silvox (12.07 ppm) and $\mathrm{AgNO}_{3}$ (12.30 ppm). It was also observed that more or less all the chemicals proved themselves to be better than check chemical Isoprothiolane (21.82 ppm). Hence, these above observation are in agreement with the findings of Gang-su Hyon et al., 2010. They noticed that role of $\mathrm{H}_{2} \mathrm{O}_{2}$ had some inhibitory effects against the microbial pathogenicity and fungal penetration to host epidermis, due to decrease of $\mathrm{H}_{2} \mathrm{O}_{2}$ production, there was a failure in penetration by the pathogen.

Table 1: Regression and correlation of toxicity of chemicals against Colletotrichum capsici (Mycellial Growth Inhibition)

\begin{tabular}{|c|c|c|c|}
\hline \multirow{2}{*}{ Chemicals } & \multicolumn{3}{|c|}{ Mycellial growth inhibition(MGI) } \\
\cline { 2 - 4 } & Regression equation (RE) & Co-efficient of determination $\left(\mathbf{R}^{2}\right)$ & ED-50 (ppm) \\
\hline Silvernanoparticle (AgNPs) & $\mathrm{y}=1.178 \mathrm{x}+3.671$ & $\mathrm{R}^{2}=0.87$ & 13.42 \\
\hline $\mathrm{H}_{2} \mathrm{O}_{2}$ & $\mathrm{y}=1.068 \mathrm{x}+3.947$ & $\mathrm{R}^{2}=0.88$ & 12.66 \\
\hline $\mathrm{Silvox}$ & $\mathrm{y}=0.928 \mathrm{x}+3.995$ & $\mathrm{R}^{2}=0.970$ & 13.12 \\
\hline Chitosan & $\mathrm{y}=1.162 \mathrm{x}+3.700$ & $\mathrm{R}^{2}=0.909$ & 13.45 \\
\hline Salicylic acid & $\mathrm{y}=0.947 \mathrm{x}+3.931$ & $\mathrm{R}^{2}=0.855$ & 12.30 \\
\hline AgNO & $\mathrm{y}=0.817 \mathrm{x}+4.107$ & $\mathrm{R}^{2}=0.780$ & 21.82 \\
\hline $\begin{array}{c}\text { Isoprothiolane } \\
\text { (check chemical) }\end{array}$ & $\mathrm{y}=1.384 \mathrm{x}+3.146$ & $\mathrm{R}^{2}=0.978$ & \multirow{2}{*}{} \\
\hline
\end{tabular}

$\mathrm{X}=$ Probit value of percentage inhibition; $\mathrm{Y}(\mu \mathrm{g} / \mathrm{ml})=$ Antilog of the value obtained from

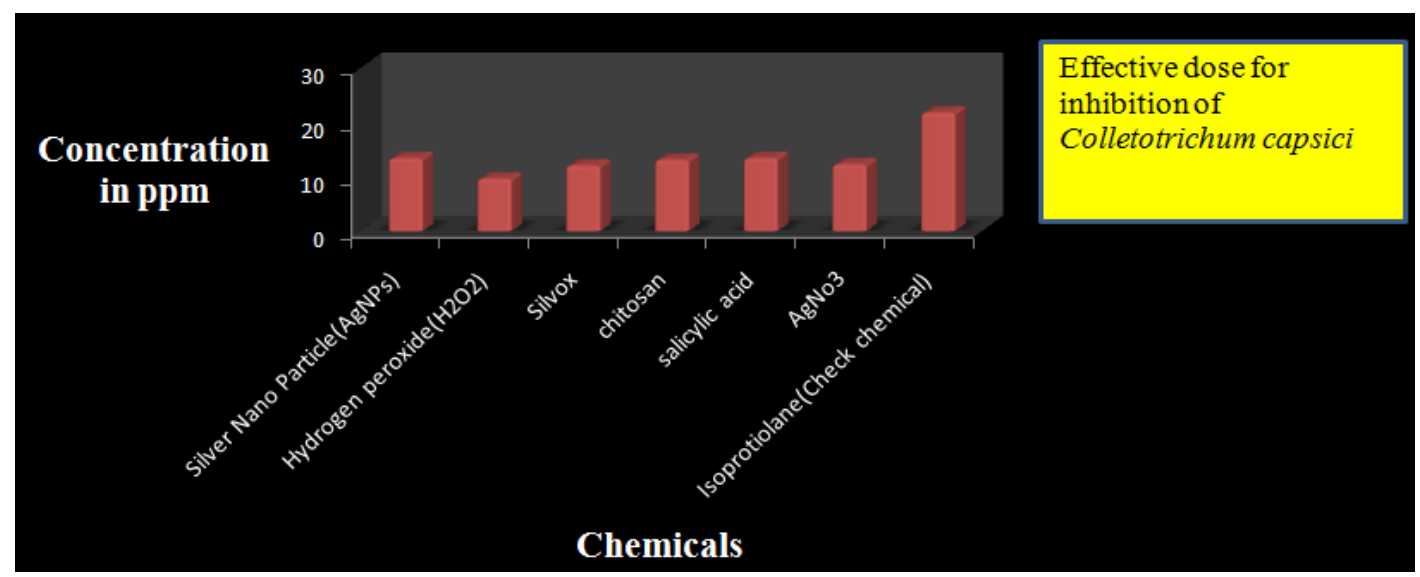

Fig 1: In-Vitro Testing of Chemicals against Colletotrichum capsici (Mycelia Growth Inhibition) 

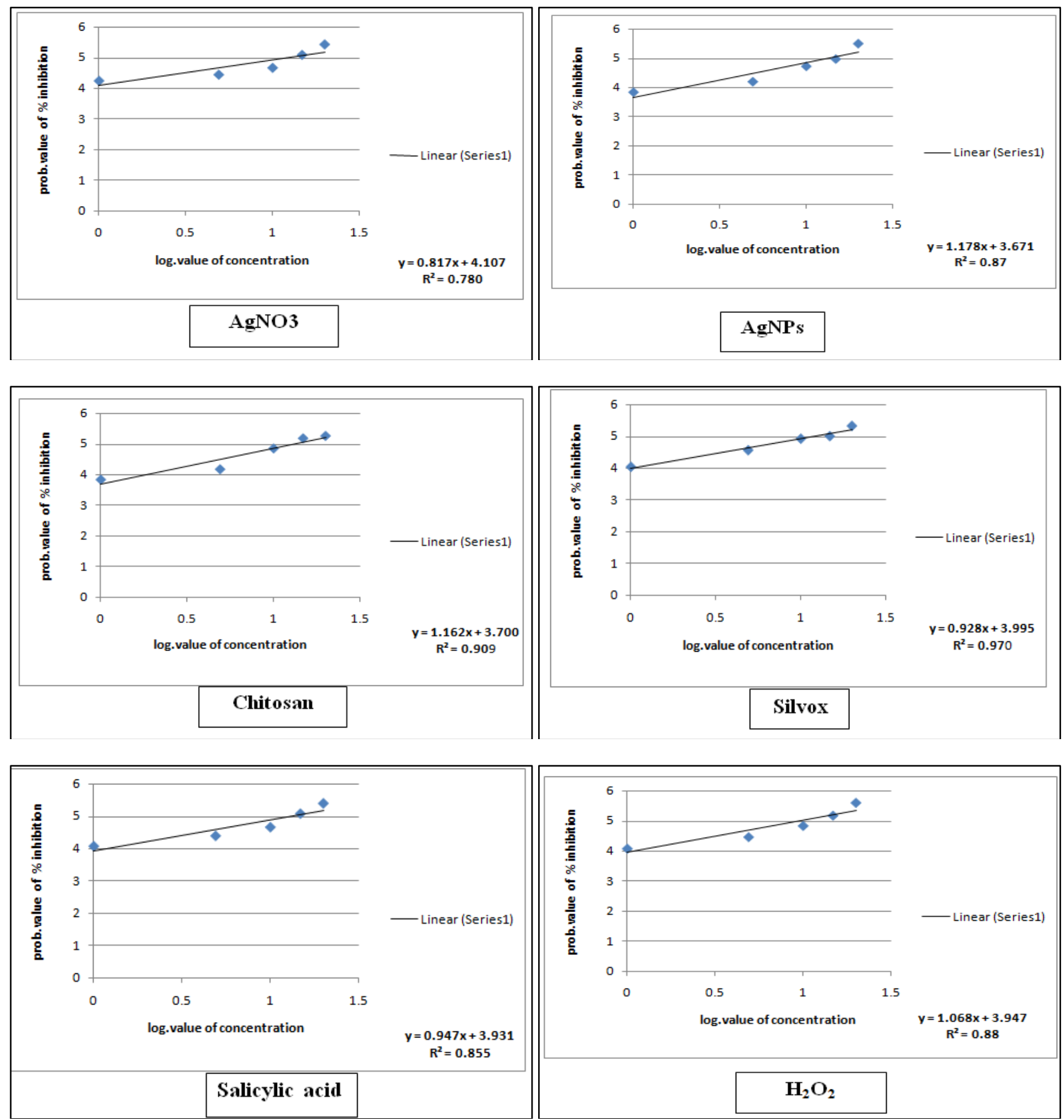

\section{Salicylic acid}

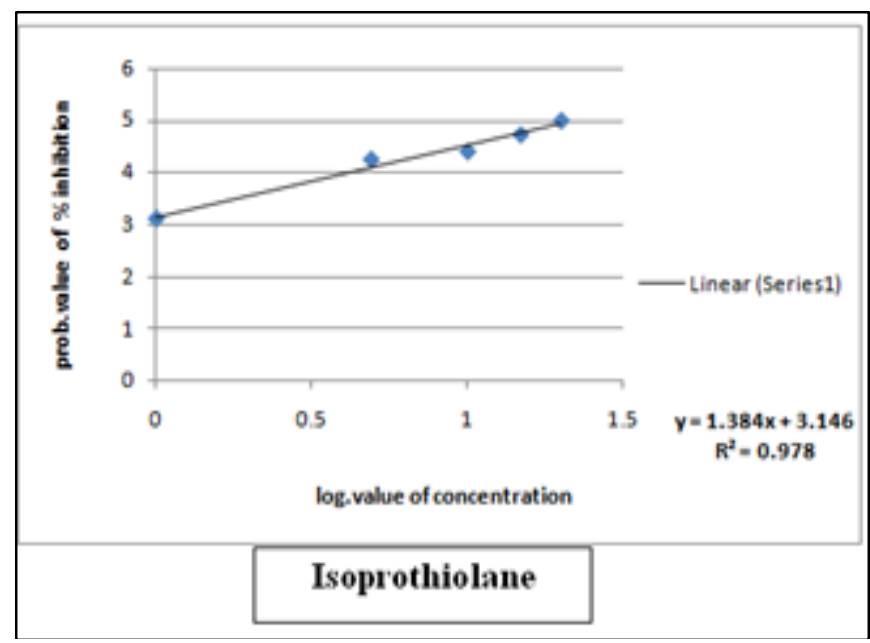

Fig 2: Graph of Prob. Value of percentage inhibition data with log. Value of concentration of chemicals used in in-vitro testing against Collectotrichum capsici 


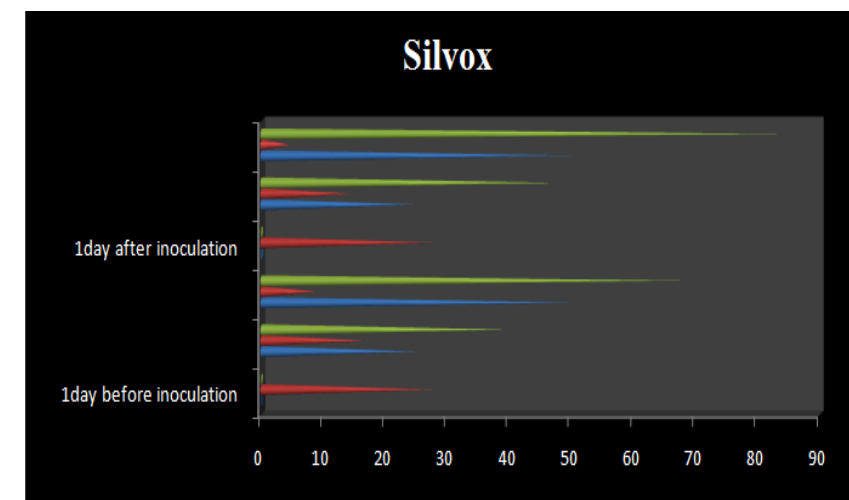

TMercent of disease severity decrease over control(\%) W severity \% W concentration(ppm)

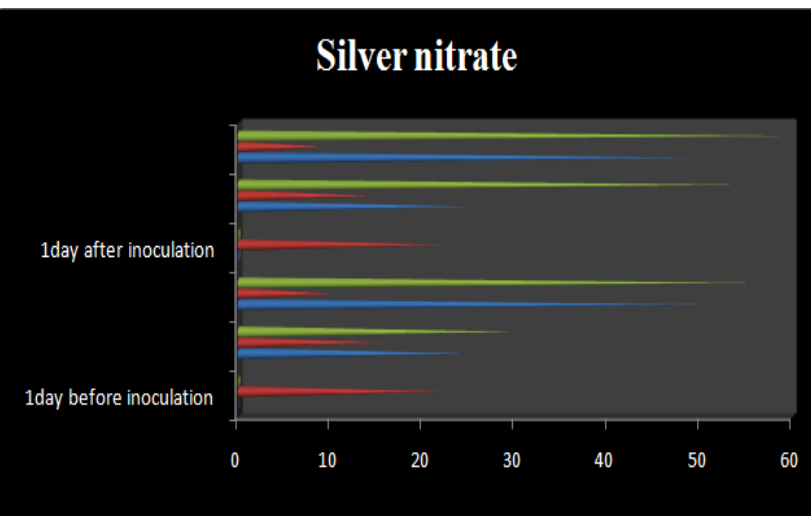

M Percent of disease severity decrease over control(\%) $\mathbf{n}$ severity \% $\mathbf{m}$ concentration(ppm)
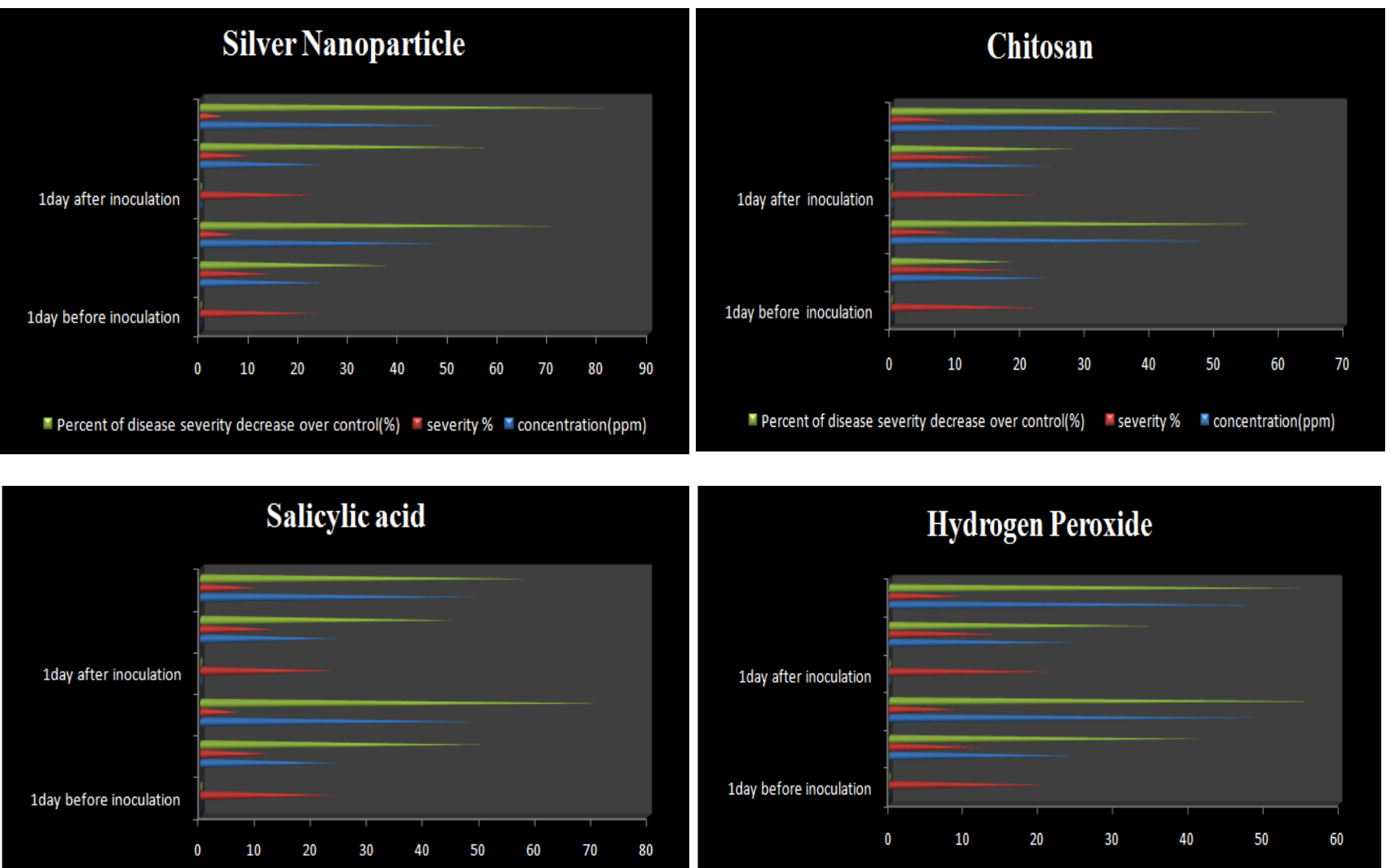

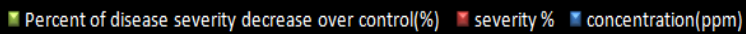

\section{Hydrogen Peroxide}

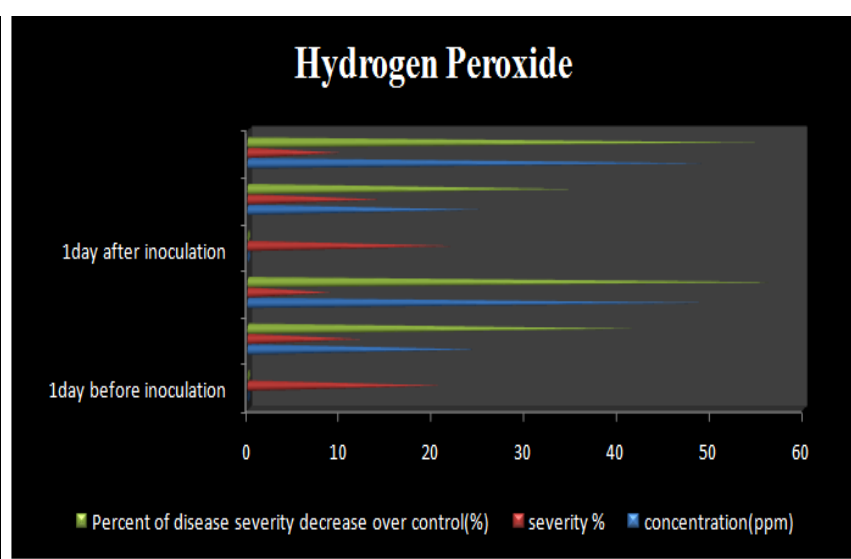

I Percent of disease severity decrease over control(\%) $\mathbf{\Psi}$ severity \% $\mathbf{\mathbf { x }}$ concentration(ppm)

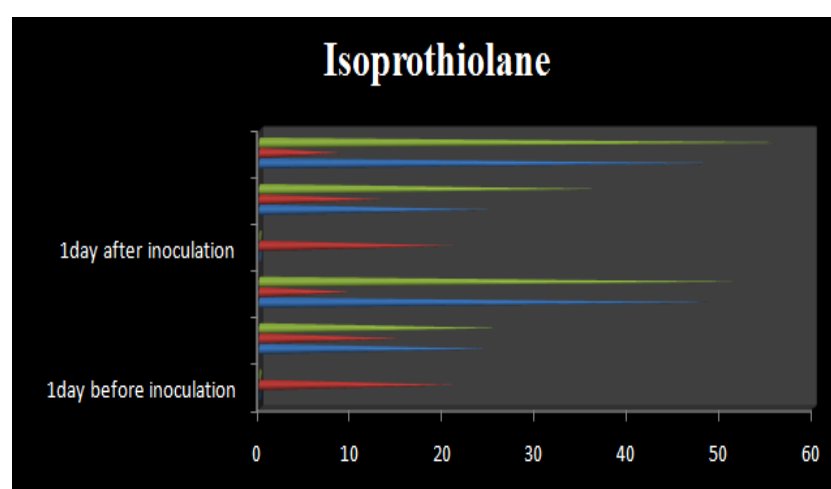

W Percent of disease severity decrease over control(\%) $\mathbf{v}$ severity \% concentration(ppm)

Fig 3: Potency of Nano and inducer chemicals against Leaf Spot causing Colletotrichum capsici pathogen on Chilli under Net House Condition 


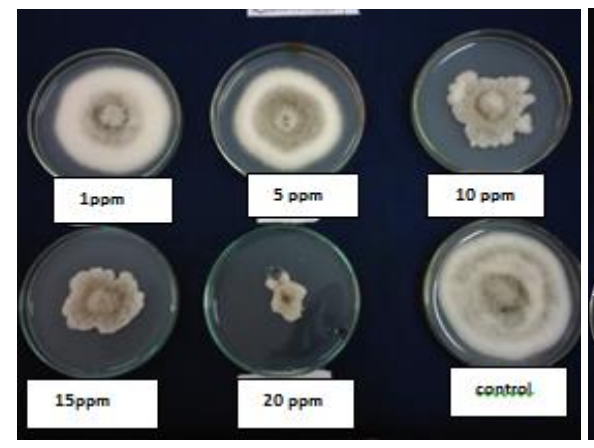

In-vitro effect of Chitosan

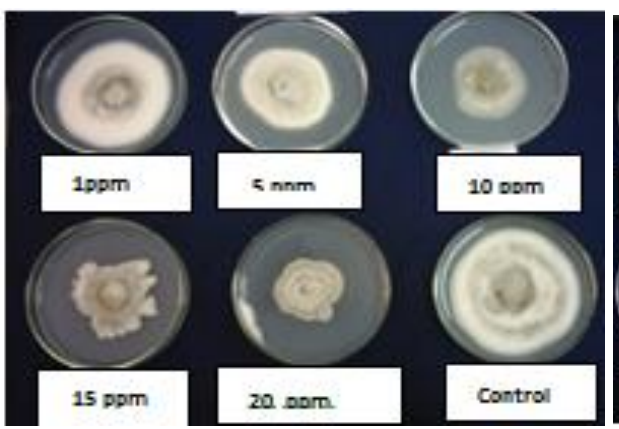

In-vitro effect of $\mathrm{AgNO}_{3}$

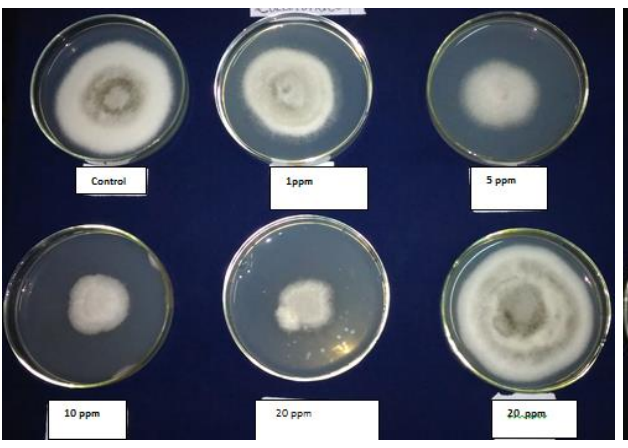

In-vitro effect of AgNPs

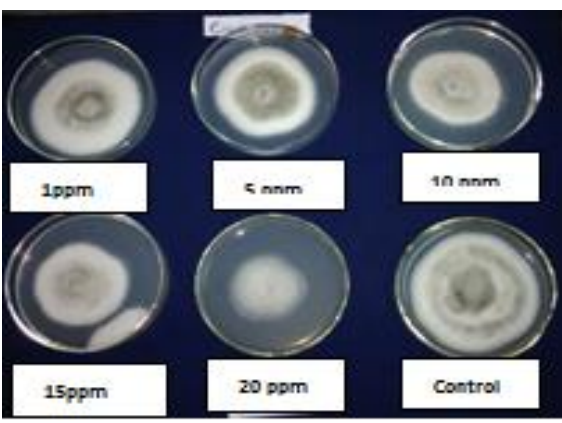

In-vitro effect of Salicylic acid

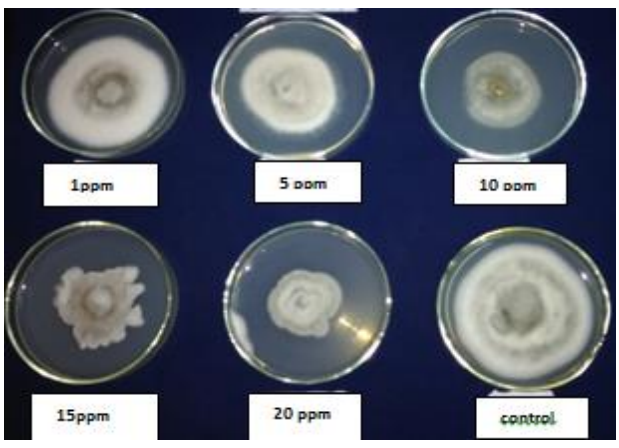

In-vitro effect of Silvox
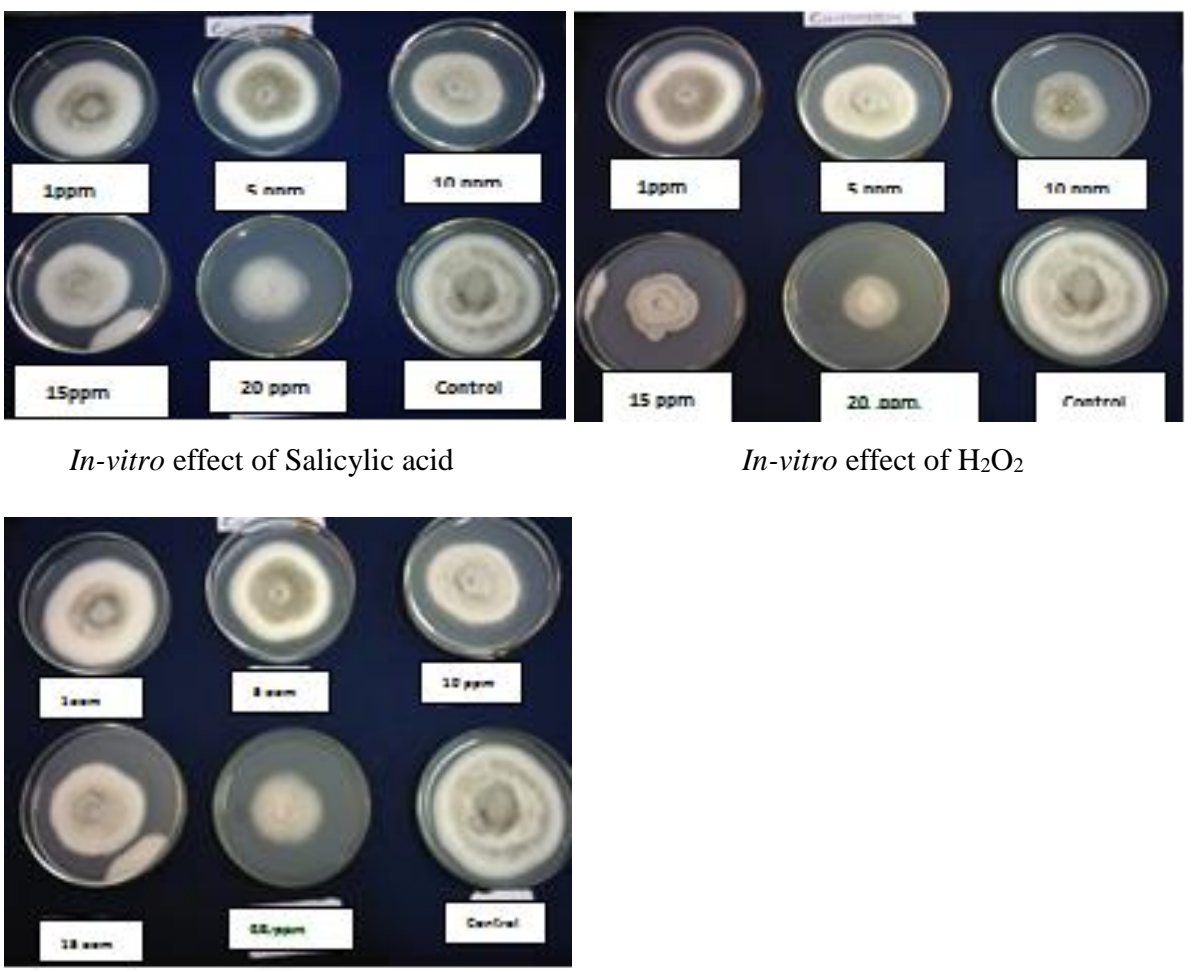

In-vitro effect of $\mathrm{H}_{2} \mathrm{O}_{2}$

In-vitro effect of Isoprothiolane

Plate 1: In-Vitro Study of responsiveness of Colletotrichum capsici against 7 Different Chemicals

The figure (3) indicated that curative application (spraying 1 day after pathogen inoculation) of mentioned nanoformulation (Silver Nanoparticle, Silvox, Chitosan, Silver nitrate)manifest significant disease suppression in compared to prophylatic application (spraying 1 day before pathogen inoculation).Application of nano formulation as curative measure gave significant result at $50 \mathrm{ppm}$ (Silver Nanoparticle-(AgNPs)-80.96\%, $\mathrm{AgNO}_{3}-60 \%$, Silvox-84.01\% and Chitosan-61.93\%) applied after onset of disease.

From the figure (3) at was indicated that inducer chemical (salicylic acid, Hydrogen peroxide) inhibited growth of pathogen only due to prophylatic way rather than curative ones. All the chemical give good result than check chemical Isoprothiolane.

\section{Conclusion}

From the above discussion it is concluded that out of seven chemical considered for the in-vitro study, $\mathrm{H}_{2} \mathrm{O}_{2} @ 9.66 \mathrm{ppm}$ found to be most effective in respect of mycelia growth inhibitation against the pathogen Colletotrichum capsici. The second best result was found in case of Silvox (12.07 ppm) followed by $\mathrm{AgNO}_{3}(12.30 \mathrm{ppm})$. as compared to check chemical Isoprothiolane.Under net house condition it recorded that curative application of nano-formulation resulted significant disease suppression at 50ppm (Silver Nanoparticle-(AgNPs)-80.96\%, $\mathrm{AgNO}_{3}-60.0 \%, \quad$ Silvox$84.01 \%$ and Chitosan-61.93\%) as compared to check chemical Isoprothiolane $(57.93 \%)$ at $50 \mathrm{ppm}$.

\section{Reference}

1. Agrios GN. Plant Pathology, 5th Ed. Academic Press, San Diego, 2005, 922.

2. Booth C, Sutton BC. Fusarium pallidoroseum, the correct name for $F$. semitectum. Transactions of British Mycological Society. 1984; 23:702-704.

3. Chowdhry PN, Lal SP, Mathur N, Singh DV. Manual on identification of plant pathogenic and biocontrol fungi of agricultural importance. Center of Advanced Studies in Plant Pathology, Indian Agricultural Research Institute, New Delhi, 2000, 149.

4. Gang-Su Hyon, Ken-ichi Ikeda, Naoki Hosogi, Takeshi Shinogi, Pyoyun Park. Inhibitory Effects of Antioxidant Reagent in Reactive Oxygen Species Generation and Penetration of Appressoria of Alternaria alternate Japanese Pear Pathotype The American Phytopathological Society 2010; 100(9):840-846

5. Hawkes JG. The economic importance of the family Solanaceae. In Solanaceae IV: Advances in Biology and 
Utilization. M Nee, DE Symon, RN Lester and JP Jessop (Eds). Royal Botanic Gardens, Kew, UK. 1999, 1-8.

6. Lamsal K, Kim SW, Jung JH, Kim YS, Kim KS, Lee Y S. Application of silver nanoparticles for the control of Colletotrichum species In vitro and pepper anthracnose disease in field. Mycobiology. 2011a; 39:194-199.

7. Manandhar JB, Hartman GL, Wang TC. Conidial germination and appressorial formation of Colletotrichum Capsici and Colletotrichum gloeosporoides isolates from pepper. Plant disease. 1995; 79(4):361-366.

8. Manandhar JB, Hartman GL, Wang TC. Anthracnose development on pepper fruits inoculated with Colletotrichum gloeosporioides. Plant Disease. 1995; 79:380-383.

9. Mayee CD, Datar VV. Phytopathometry, Technical Bulletin-1 (Special Bulletin-3) Marathwada Agricultural University, Parbhani, Maharashtra, India, 1986, 95.

10. Maziah Z. Colletotrichum diseases of forest tree nurseries in Malaysia. Ph.D. thesis, University of Bristol, United Kingdom. 1995, 222.

11. McKenzie EKD, Cai L, McKenzie EHC, Yang YL, Zhang JZ, Prihastuti H. Colletotrichum: A catalogue of confusion. Fungal Diversity. 2009; 39:1-17.

12. Phoulivong S, Cai L, Chen H, McKenzie EHC, Abdelsalam K, Chukeatirote ED et al. Colletotrichum gloeosporioides is not a common pathogen on tropical fruits. Fungal Diversity. 2010, 33-43.

13. Poonpolgul S, Kumphai S. Chilli Pepper Anthracnose in Thailand. Country Report. In: Oh DG, Kim KT, editors. Abstracts of the First International Symposium on Chilli Anthracnose. Republic of Korea: National Horticultural Research Institute, Rural Development of Administration, 2007, 23.

14. Vincent JM. Distortion of fungal hyphae in the presence of certain inhibitors. Nature. 1947; 159:850-850

15. Voorrips RE, Finkers R, Sanjaya L, Groenwold R. QTL mapping of anthracnose (Colletotrichum spp.) resistance in a cross between Capsicum annuum and C. chinense. Theoretical and Applied Genetics. 2004; 109(6):12751282. 